\title{
Fenton's oxidation of Orange II solutions using heterogeneous catalysts based on saponite clay
}

\author{
J. Herney Ramirez ${ }^{1}$, Carlos A. Costa ${ }^{1}$, Luis M. Madeira ${ }^{1 \star}$, G. Mata ${ }^{2}$, Miguel A. Vicente ${ }^{2}$, M.L. Rojas- \\ Cervantes $^{3}$ and R.M. Martín-Aranda ${ }^{3}$ \\ 'LEPAE - Departamento de Engenharia Química, Faculdade de Engenharia da Universidade do Porto. Rua Dr. \\ Roberto Frias, 4200-465 Porto, Portugal; ${ }^{2}$ Departamento de Química Inorgánica. Universidad de Salamanca. Plaza \\ de la Merced, S/N. E-37008 Salamanca, España; ${ }^{3}$ Departamento de Química Inorgánica y Química Técnica, \\ Facultad de Ciencias, UNED, Paseo Senda del Rey no. 9, Madrid 28040, España.
}

\begin{abstract}
Fe-clay catalysts have been prepared and tested for Orange II oxidation with $\mathrm{H}_{2} \mathrm{O}_{2}$ in aqueous solution. The reaction is carried out in a batch reactor, using different hydrogen peroxide concentrations, and in a wide range of temperature and $\mathrm{pH}$ values. Twelve samples were prepared, with three different iron loads $(7.5,13.0$ and $17.0 \%$, $\mathrm{w} / \mathrm{w})$, and using four iron salts as precursors, namely $\mathrm{Fe}(\mathrm{II})$ acetate, $\mathrm{Fe}(\mathrm{II})$ oxalate, $\mathrm{Fe}(\mathrm{II})$ acetylacetonate and $\mathrm{Fe}(\mathrm{III})$ acetylacetonate. The samples were characterized using X-ray diffraction, thermal analysis, infrared spectroscopy and adsorption of nitrogen at 77K. The catalytic results show that these solids present good catalytic properties for the degradation and mineralization of Orange II solutions, allowing to reach, in the best conditions and after $4 \mathrm{~h}$ of oxidation, $99 \%$ of dye degradation with $91 \%$ of TOC (Total Organic Carbon) reduction (at $70^{\circ} \mathrm{C}$ ), using only ca. $90 \mathrm{mg}$ of clay catalyst per litre of solution. Nevertheless, $96 \%$ of dye removal with $82 \%$ of mineralization were also reached at $30^{\circ} \mathrm{C}$. Besides, the amount of iron released into the final solution is lower than $1 \mathrm{ppm}$, in the worst of the cases, and $0.09 \mathrm{ppm}$ in the best case.
\end{abstract}

Keywords Clay-Fe catalysts, Fenton's reagent, Heterogeneous catalysis, Orange II, Oxidation.

\section{Introduction}

The reaction of hydrogen peroxide with ferrous ion in acidic aqueous solutions (Fenton's reagent) can be used as source of hydroxyl radicals for the degradation of organic pollutants in wastewater treatment (Gallard and Laat, 2001). The $\mathrm{HO}^{\circ}$ radicals generated through reaction (1) are highly oxidative, non-selective, and able to decompose many organic compounds, including dyes (Swaminathan et al., 2003).

$$
\mathrm{Fe}^{2+}+\mathrm{H}_{2} \mathrm{O}_{2} \rightarrow \mathrm{Fe}^{3+}+\mathrm{OH}^{-}+\mathrm{HO}^{\circ}
$$

However, the homogeneous Fenton process has a significant disadvantage: the removal of the sludge-containing Fe ions at the end of wastewater treatment is expensive and needs large amount of chemicals and manpower. To overcome this disadvantage some attempts have been made to develop heterogeneous Fenton process by means of heterogeneous catalysts, prepared by incorporating Fe ions or Fe oxides onto porous supports (Gemeay et al., 2003; Letaief et al., 2003). Transition metal complexes supported on different surfaces such as metal oxides, resins, and mixed (Al-Cu) pillared clay have also been used as potentially active catalysts for the decomposition of $\mathrm{H}_{2} \mathrm{O}_{2}$ and the oxidative degradation of organic contaminants. Among the porous solids used as supports for the iron phases, some are based on silica, alumina, silica-alumina and cation-exchanged resins, and all these catalysts have been used for degradation and mineralization of dyes (Gemeay et al., 2003). It is also important to remark the use of catalysts prepared by co-intercalation of two natural smectites (Wyoming SWy-1 and Tunisia-Gafsa VI) with Fe-Al polycations, obtained by polymerisation of a mixture of $\mathrm{FeCl}_{3}$ and chlorhydrol (Letaief et al. 2003).

Pillared clays (PILCs) are one of the families of microporous solids developed by Molecular Engineering more studied in recent years. The PILCs are prepared by intercalation of appropriate polyoxocations into the clay, followed by calcination at relatively high temperatures (Belver et al., 2004), showing a bidimensional microporous network of molecular dimensions, with the pillars occupying the interlayer space defined by the clay layers. Alternatively, it can be said that the clay layers avoid the aggregation of the metallic oxide clusters, giving rise to much dispersed particles. The number and size of the pillars in the interlayer region condition the pore parameters of the pillared clay structure (Vicente et al., 2000).

In this work, several heterogeneous catalysts based on saponite impregnated with iron salts were prepared. A saponite has been intercalated with $\mathrm{Al}$ polycations, and the pillared solid obtained after calcination at $500^{\circ} \mathrm{C}$ has been used as support for impregnation with iron. Four Fe-precursors have been used and for each one three different loads of iron (7.5, 13.0 and 17.0 Fe wt. \% in the final catalysts) were considered. The obtained heterogeneous 
catalysts are used in the oxidation of the non-biodegradable dye Orange II (O-II) in water solution, using a batch reactor, and carrying out experiments under a wide range of experimental conditions. The effectiveness of these catalysts in the oxidation of the dye, as well as the influence of the variables of the synthesis and of the conditions of reaction in the catalytic activity, are discussed.

\section{Methods}

\section{Preparation of the catalysts}

Saponite clay from Yunclillos (Toledo, Spain) was kindly supplied by TOLSA (Madrid, Spain). The fraction with particle size smaller than $2 \mu \mathrm{m}$ was obtained by dispersion in water and controlled decantation of the natural clay, and was then used for intercalation/pillaring experiment. It is a well ordered smectite with basal spacing of $14.4 \AA$, BET specific area of $152 \mathrm{~m}^{2} / \mathrm{g}$ and cation exchange capacity (CEC) of $0.9 \mathrm{meq} / \mathrm{g}$.

Saponite was intercalated with $\left[\mathrm{Al}_{13} \mathrm{O}_{4}(\mathrm{OH})_{24}\left(\mathrm{H}_{2} \mathrm{O}\right)_{12}\right]^{7+}$ polycations (in short, $\mathrm{Al}_{13}$ ) by using a standard procedure (Bottero, et al., 1980; Lahav, et al., 1978). First, intercalating $\mathrm{Al}_{13}$ solution was obtained by careful hydrolysis of an $\mathrm{Al}^{3+}$ solution, derived from $\mathrm{AlC}_{13} \cdot 6 \mathrm{H}_{2} \mathrm{O}$ (Panreac, purissimum), with $1 \mathrm{M} \mathrm{NaOH}$ (Panreac, purissimum), using a ratio $\mathrm{OH}^{-} / \mathrm{Al}^{3+}=2.2$, stirring vigorously and aging $24 \mathrm{~h}$ (final $\mathrm{pH}=4.1$ ). Once the solution was aged, it was added to a previously (12 hours) prepared suspension of saponite in water, employing an Al/clay ratio of $5 \mathrm{mmol} / \mathrm{g}$. The new suspension was stirred for $24 \mathrm{~h}$, and then washed by centrifugation and dialysis until absence of chloride $\left(\mathrm{Ag}^{+}\right.$test). The solid obtained was dried at $70^{\circ} \mathrm{C}$ for $16 \mathrm{~h}$, and then heated to $500^{\circ} \mathrm{C}$ at a heating rate of $1{ }^{\circ} \mathrm{C} / \mathrm{min}$ and maintained at this temperature for four hours. The solid obtained was used as support for impregnation. As this is the support used for the preparation of all supported catalysts, it may always be referred to as "the support".

Impregnation was carried out by means of the incipient wet impregnation method. As indicated, $\mathrm{Al}_{13}$-pillared saponite was always used as support, and four different Fe-salts as precursors (Fe(II) acetate, $\mathrm{Fe}$ (II) oxalate, Fe(II) acetylacetonate and Fe(III) acetylacetonate). For each precursor, the amounts needed for obtaining 7.5, 13.0 and 17.0 Fe wt. $\%$ in the final catalysts were calculated. These amounts were dissolved in the minimum amount of the appropriate solvent (water for the acetate and the oxalate, and acetone for both acetylacetonates), the obtained solutions being used for the impregnation. The first two precursors were very soluble and a single impregnation step was needed, while five cycles were needed for both acetylacetonates because of their low solubility. After completing the impregnation, the solids were calcined at $500^{\circ} \mathrm{C}$ following the calcination procedure described above, thus obtaining the final catalysts. These catalysts are designated by a precursor-amount notation, for example $\mathrm{Fe}$ (II) acetate-7.5 designates the solid prepared using as precursor Fe(II) acetate and containing 7.5 wt. \% of Fe in the final catalysts.

\section{Characterization of the catalysts}

- Powder X-ray diffraction patterns (XRD) of the solids were recorded using a Siemens D-500 diffractometer at 40 $\mathrm{kV}$ and $30 \mathrm{~mA}$ using filtered $\mathrm{Cu} \mathrm{K}_{\alpha}$ radiation $(\lambda=1.5418 \AA$ A) over a $2 \theta$ range from 2 to 65 degrees.

- FT-Infrared spectra were recorded in the $4000-350 \mathrm{~cm}^{-1}$ region with a Perkin-Elmer 1730 FT-IR spectrometer, using a He-Ne laser source $(\lambda=632.8 \mathrm{~nm})$, in $\mathrm{KBr}$ pellet $(0.001 \mathrm{~g}$ sample with $0.3 \mathrm{~g} \mathrm{KBr})$, and 15 scan per minute to improve the signal-to-noise ratio.

- BET specific surface areas were determined by adsorption of nitrogen at $77 \mathrm{~K}$, measuring five adsorption points by using a Micromeritics Gemini apparatus.

- Simultaneous thermal gravimetric (TG) and differential scanning calorimetric (DSC) analyses of samples were carried out using a TA-SDT Q600 Instrument. Samples of about $40 \mathrm{mg}$ were heated in air (flow rate $=100$ $\mathrm{mL} / \mathrm{min}$ ) from room temperature up to $900{ }^{\circ} \mathrm{C}$, with a heating rate of $10^{\circ} \mathrm{C} \mathrm{min}^{-1}$.

\section{Catalytic activity}

Chemical oxidation of $0.1 \mathrm{mM}$ Orange II (Fluka p.a.) solutions was carried out in a batch reactor of $1 \mathrm{~L}$ of capacity, with constant stirring by means of a FALC F30ST magnetic stirrer $(230 \mathrm{rpm})$, and with a permanent control of the temperature by a thermostatic bath (Huber, Polystat $\mathrm{CC} 1$ unit). After stabilisation of temperature and $\mathrm{pH}$, the catalyst was added, and the beginning of the reaction $(t=0)$ was taken when $\mathrm{H}_{2} \mathrm{O}_{2}$ was added. Absorbance, temperature and $\mathrm{pH}$ were permanently measured by means of a Philips PU8625 UV/VIS spectrophotometer, a 
temperature sensor, and a pH EDT Instruments RE 357 TX electrode, respectively. For the on-line determination of the absorbance at $\lambda=486 \mathrm{~nm}$ (characteristic wavelength of the Orange II molecule) a flow-through cell was used, and recirculation was obtained by a peristaltic Watson-Marlow 5055 pump, using a flow-rate of $100 \mathrm{~mL} / \mathrm{min}$. Acquisition of data was carried out by Labview 5.0 software, from National Instruments. The total duration of each oxidation experiment was 4 hours. In several cases, Total Organic Carbon (TOC) was measured using a Shimadzu 5000A spectrophotometer, model TOC-5000 CE, equipped with an automatic sample injector. After taking the sample and before measuring TOC, reaction was stopped by adding $\mathrm{Na}_{2} \mathrm{SO}_{3}$ (that instantaneously consumes $\mathrm{H}_{2} \mathrm{O}_{2}$ ), followed by centrifugation and filtration for the perfect separation of the catalyst from the liquid phase. The total Fe in the final solution was determined using a UNICAM 939/959 atomic absorption spectrophotometer.

\section{Results and discussion}

\section{Characterization of the Catalysts}

Intercalation/pillaring experiment was carried out under standard conditions, and goes in a successful way. The solid intercalated with $\mathrm{Al}_{13}$ polycations and then calcined at $500^{\circ} \mathrm{C}$, used as support for further experiments, shows the typical features of Al-PILCs. It has a layered structure with a basal spacing of $18.2 \AA$ (Fig. 1A), and a specific surface area of $240 \mathrm{~m}^{2} / \mathrm{g}$. The impregnated solids maintain the layered structure, but with a remarkable loss of ordering compared to the support. These catalysts, once calcined at $500^{\circ} \mathrm{C}$, show a weak diffraction effect, between 16.8 and 17.3 $\AA$ (Fig. 1A). However, as can be observed in these diffractograms, although the long-range ordering in the c-axis is low, it is not negligible, and all solids show a certain degree of layered-structure ordering. At the same time, the impregnation-drying process, mainly in the solids treated with acetylacetonate solutions, for which various impregnation cycles are needed, and the further calcination at $500^{\circ} \mathrm{C}$, produce a certain collapse and delamination of the structure. Reflections independent of c-axis ordering do not show any variation with respect to the support, indicating that the impregnation does not affect the individual layers, but only their stacking. On the other hand, it may be underlined that no peaks due to iron phases are observed in the diffractograms. Considering the preparation method used and the results obtained from other techniques, it may be reasonably expected that phases close to $\mathrm{Fe}_{2} \mathrm{O}_{3}$ be formed after calcination of the impregnated solids at $500^{\circ} \mathrm{C}$, by the removal of the organic moieties of the precursors, and oxidation, if needed, of iron. However, no oxides, neither oxi-hydroxides, peaks are found in the diffractograms, although the amounts of iron used in the impregnations are relatively high. So, it may be proposed that iron is as a very disperse phase on the surface of the support.

FT-IR spectra of the support and of various impregnated solids, both dried and calcined, are shown in Fig. 1B. The support has the bands characteristic of Al-PILCs. Thus, in the high wavenumber region, the spectrum is dominated by the stretching vibrations of the hydroxyl groups bonded to metallic cations and to water molecules. Bending of water molecules also produces an important effect close to $1630 \mathrm{~cm}^{-1}$, while the bands characteristic of the tetrahedral layer of the clay dominate the region of low wavenumbers, being the Si-O-Si band, at $1007 \mathrm{~cm}^{-1}$, the more intense of the spectrum, and appearing at lower wavenumbers the bands due to $\mathrm{M}-\mathrm{O}$ bonds in the octahedral layer (mainly $\mathrm{Mg}-\mathrm{O}$ and $\mathrm{Fe}-\mathrm{O}$, because of the chemical nature of saponite). Solids impregnated and dried show, in all cases, the bands due to the support, also showing bands assigned to the precursors. The bands due to the support do not show important variations with respect to the support before impregnation, only small differences in intensity. This is an expectable observation, because of the low influence of the impregnation on the structural bonds of the clay, where only surface hydroxyl groups may be affected, giving rise to interfacial coordination bonds with $\mathrm{Fe}^{2+}$ and $\mathrm{Fe}^{3+}$ cations from the precursors. On the other hand, the effects due to the precursors are strongly intense, as can be expected because precursors containing organic moieties have been employed. The characteristic bonds of each precursor are observed in each case, with characteristic vibrations of $\mathrm{C}-\mathrm{H}$ bonds, carboxylate or carbonyl groups, etc. All these effects completely disappear when calcining the impregnated solids at $500^{\circ} \mathrm{C}$, showing that organic moieties are completely removed at this temperature, thus transforming the precursor molecules into iron oxide-like phases. However, no peaks due to Fe-oxides, neither oxy-hydroxides, are observed in the spectra, suggesting once again a high dispersion of the iron phases.

It is noteworthy that the BET specific surface areas of all the samples (not shown for brevity) are comprised between 128 and $192 \mathrm{~m}^{2} / \mathrm{g}$, which represents a percentage of $53-80 \%$ of the value of the support. These values are relatively high considering the subsequent steps of the preparation of the catalysts, including impregnation, drying, and calcination at $500^{\circ} \mathrm{C}$. 
The thermogravimetric analyses curves of some of the impregnated samples (with Fe(II) oxalate) are displayed in Fig. 1C. Several weight losses can be observed. The removal of adsorbed water and physisorbed solvent occurs until ca. $150^{\circ} \mathrm{C}$, while the decomposition of the organic precursors occurs at higher temperatures $\left(150-425^{\circ} \mathrm{C}\right)$. The final weight loss observed in all cases in the $415-825^{\circ} \mathrm{C}$ range is due to the dehydroxilation of the clay. For all samples, it is clear that the temperature of calcination guarantees the removal of the organic fragments and the obtaining of iron-like phases. The DSC curves for the samples containing $13 \%$ wt. of Fe are shown in Fig. 1D. An endothermic peak is observed in the $30-150{ }^{\circ} \mathrm{C}$ for the sample containing acetate, as consequence of the highest weight loss of adsorbed water and solvent detected in the TG curve of this sample, with respect to those prepared with other precursors. The DSC peak corresponding to the decomposition of the most part of the organic material is centred at around $315{ }^{\circ} \mathrm{C}$ for acetate, $275^{\circ} \mathrm{C}$ for $\mathrm{Fe}(\mathrm{II})$ acetylacetonate and $350{ }^{\circ} \mathrm{C}$ for oxalate and $\mathrm{Fe}(\mathrm{III})$ acetylacetonate. For these last three samples, other exothermic peaks of lower intensity can be observed in the $150-275^{\circ} \mathrm{C}$ with associated weight losses in their corresponding TG curves. The removal of the last hydroxyl groups in the clay is observed as a clear weight loss close to $800^{\circ} \mathrm{C}$, associated to an endothermal effect, and once this dehydroxilation is completed, it is followed by an exothermal effect corresponding to the phase transformation from saponite to enstatite, not associated with any weight loss in the TG curves. No peaks that could be associated to transformation of iron phases are observed.
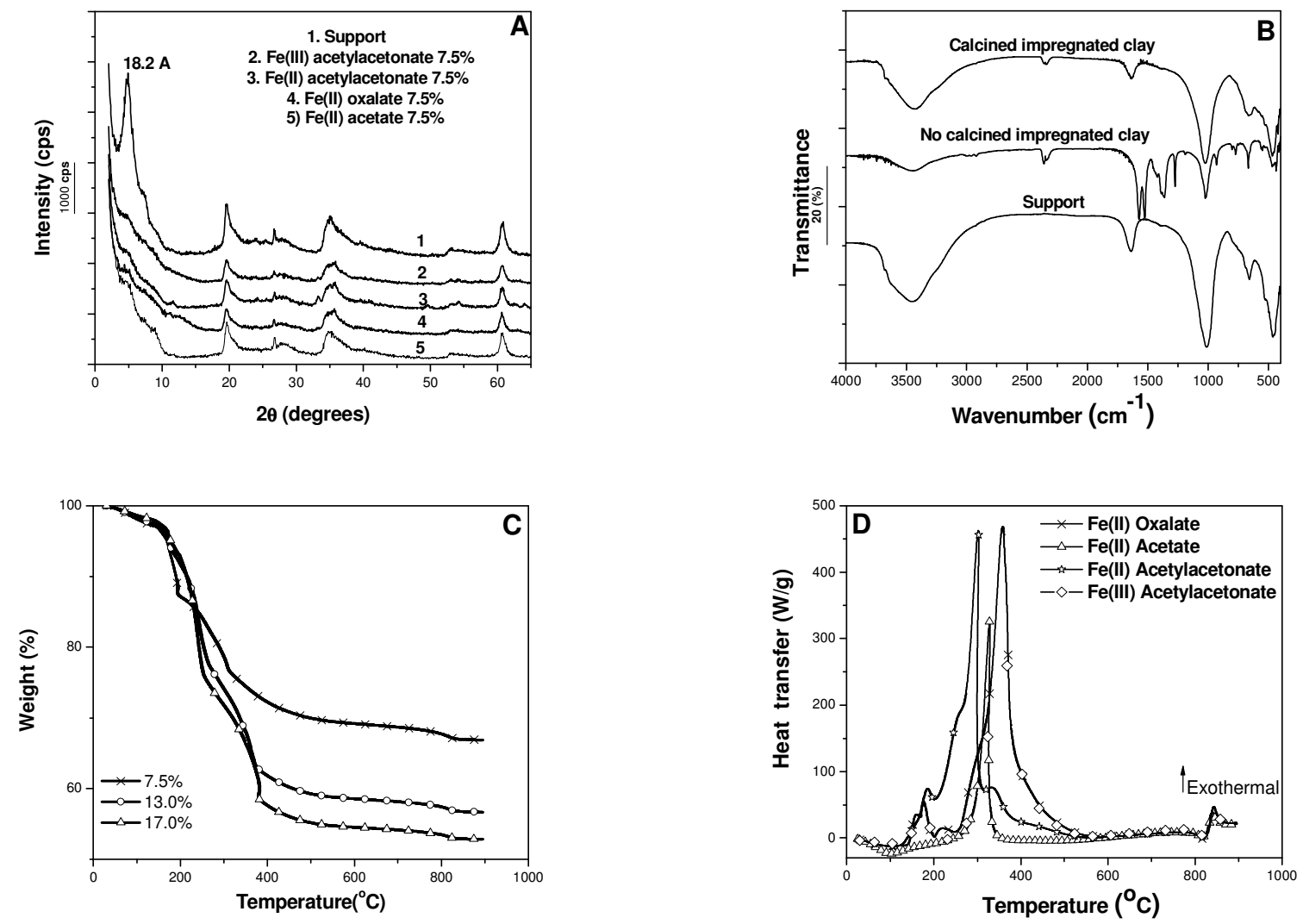

Figure 1. Characterization of the catalysts: (A) XRD of the support and catalysts with $7.5 \mathrm{wt} . \%$ of iron calcined at $500^{\circ} \mathrm{C}$, (B) FTIR of the support and impregnated solid with Fe(II) oxalate 17.0, before and after the calcination, (C) Thermogravimetric analysis of different dried samples impregnated with Fe(II) oxalate and (D) DSC curves of the samples impregnated with 13.0 wt. \% of Fe.

\section{Catalytic behaviour}

Although the natural clay has already some iron (ca. 1 wt.\%), no degradation of the OII solution was noticed when using it as catalyst under the typical conditions adopted in this work $\left(\mathrm{C}_{\mathrm{H} 2 \mathrm{O} 2 \mathrm{o}}=6 \mathrm{mM}, \mathrm{T}=30^{\circ} \mathrm{C}, \mathrm{pH}=3, \mathrm{w}_{\text {clay }}=91.5\right.$ $\mathrm{mg} / \mathrm{L}, \mathrm{t}=4 \mathrm{~h}$ ), which may be related to the inaccessibility of such iron, located in the octahedral positions of the clay structure. Besides, there is any dye removal by adsorption (blank run in the same conditions but without hydrogen peroxide), what is due to the remarkably low concentrations of clay used in our work. Actually, the use of $w_{\text {clay }}=1$ 
$\mathrm{g} / \mathrm{L}$, an amount commonly found in the literature, provided about $36 \%$ removal by adsorption after $4 \mathrm{~h}$ (but no equilibration was yet reached).

Based in our previous work (Ramirez et al., 2006), among the twelve samples prepared two catalysts were chosen to study into more detail the effect of the temperature, $\mathrm{pH}$ and initial $\mathrm{H}_{2} \mathrm{O}_{2}$ concentration. They were those prepared with oxalate with Fe content of 7.5 and $17.0 \mathrm{wt}$ \%. In this concern, it is especially remarkable the Fe(II) oxalate 17.0 catalyst, which showed a very good behaviour in terms of mineralization (81.6\% of TOC reduction) and discoloration (95.9\% of OII removal), after $4 \mathrm{~h}$ of oxidation.

\section{Temperature effect}

The results obtained for the OII degradation at four different temperatures $\left(10,30,50\right.$ and $\left.70^{\circ} \mathrm{C}\right)$, using catalysts prepared with $\mathrm{Fe}$ (II) oxalate with 7.5 and 17.0 wt. \%, are shown in Fig. 2. The results show clearly that the reaction rate increases when increasing the temperature, which was expected due to the exponential dependency of the kinetic constants with the reaction temperature (Arrhenius law). Nevertheless, the final OII concentrations, after 4 hours of oxidation, are very similar at 50 and $70^{\circ} \mathrm{C}$. In fact, the eliminations obtained at these temperatures are already quite similar after two hours of reaction, with values around $98 \%$, whereas at $10^{\circ} \mathrm{C}$ the elimination is practically negligible (ca. $8 \%$ after $4 \mathrm{~h}$ of reaction for both samples). Other authors have also found similar results during catalytic wet peroxide oxidation of phenol over Fe-exchanged clays (Catrinescu, et al., 2003; Guo, et al., 2003), the similar performances achieved at higher temperatures being due to the accelerated decomposition of $\mathrm{H}_{2} \mathrm{O}_{2}$ into oxygen and water.

The overall TOC removal for both catalysts at different temperatures showed that, as expected, the mineralization increases with the temperature, the performances reached being better for the sample with $17.0 \%$ of Fe (Table 1). For this sample, it is remarkable that the TOC removal is near $91 \%$ at $\mathrm{T}=70^{\circ} \mathrm{C}$ and around $82 \%$ at $30^{\circ} \mathrm{C}$. Although lower than those obtained at higher temperatures, the values of OII and TOC removal achieved at $30{ }^{\circ} \mathrm{C}$ might be considered satisfactory. Taking into account that a lower temperature might reduce the process costs, $30{ }^{\circ} \mathrm{C}$ was the temperature chosen to carry out the following runs, where other parameters are changed. In addition, iron leaching is smaller at $30{ }^{\circ} \mathrm{C}$ than at $70^{\circ} \mathrm{C}$ and is not very significant after $4 \mathrm{~h}(<0.25 \mathrm{mg} / \mathrm{L}$, thus being below the value of the EU directives).
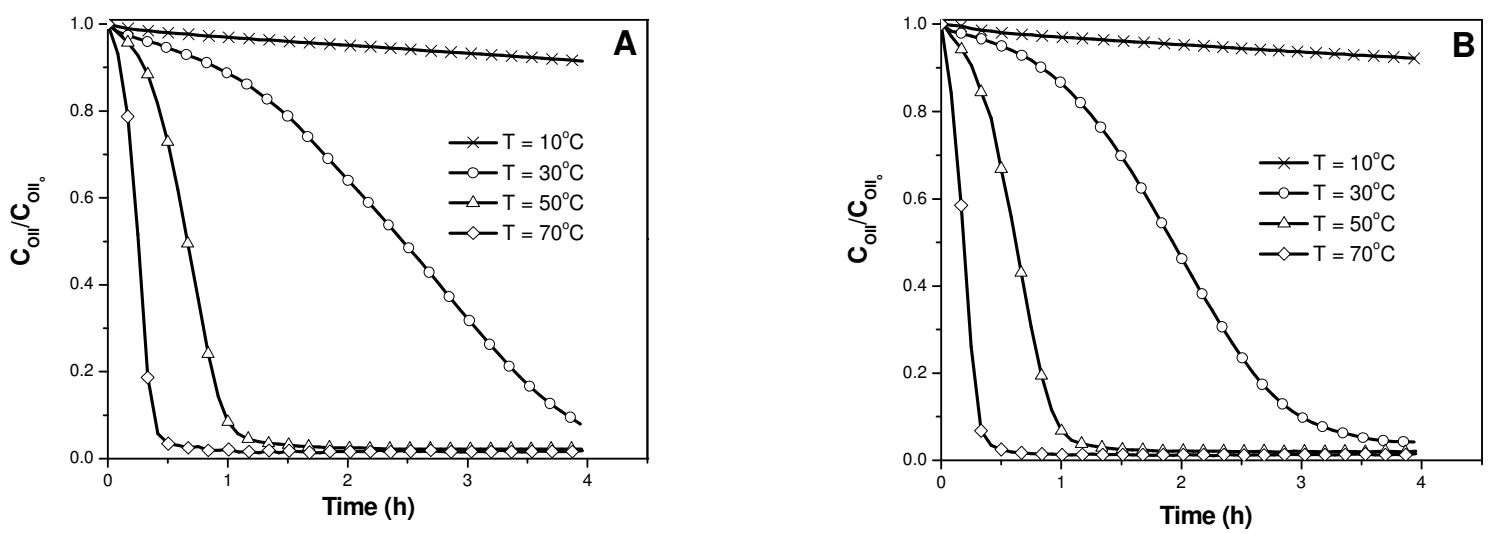

Figure 2. Temperature effect on the degradation of OII solution using different catalysts: (A) $\mathrm{Fe}(\mathrm{II})$ oxalate 7.5 wt. $\%$ and (B) $\mathrm{Fe}(\mathrm{II})$ oxalate 17 wt. $\%\left(\mathrm{pH}=3.0, \mathrm{C}_{\mathrm{H} 2 \mathrm{O} 2}=6 \mathrm{mM}\right)$.

pH effect

The results obtained for the OII degradation using the $\mathrm{Fe}(\mathrm{II})$ oxalate catalysts at three different $\mathrm{pH}$ values are

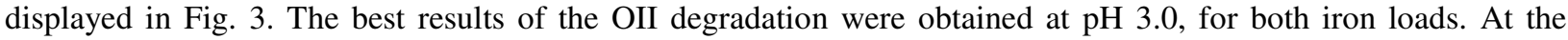
lowest value of $\mathrm{pH}$ tested, $\mathrm{pH}=2.0$, the reaction is very slow and an important increase of decolorisation activity was only noticed after ca. 2.5 hours of reaction. However, at pH 3.5 performances achieved are even worst, with color removals after $4 \mathrm{~h}$ of only 43 and $51 \%$ for 7.5 or $17.0 \mathrm{wt} . \%$ of Fe, respectively (Figs. 3A and 3B). It must be stressed that additional experiments have also been performed at $\mathrm{pH} 4.0$ (not shown for brevity) but practically no dye degradation was produced, even for much longer reaction times. Regarding TOC removal, conclusions are similar, with better performances for both samples at $\mathrm{pH} 3.0$ (Table 1). Curiously, this was exactly the best $\mathrm{pH}$ value found by Feng et al. (2006) during OII degradation using clay-based Fe nanocomposites with photo-Fenton process, with a reaction rate decrease similar to that reported by us when one deviates from such $\mathrm{pH}$ value. Other authors 
also found, using pillared clays, that the reaction rate was much higher for the $\mathrm{pH}$ value corresponding to the optimum $\mathrm{pH}$ determined when homogeneous Fe species were used as catalyst (Barrault, et al., 2000).

Table 1. TOC removal (\%) after $4 \mathrm{~h}$ of oxidation.

\begin{tabular}{ccccc}
\hline \multicolumn{2}{c}{ Experimental conditions } & \multicolumn{3}{c}{ Catalyst } \\
Temperature $\left({ }^{\circ} \mathrm{C}\right)$ & $p H$ & $C_{H 2 O 2}(\mathrm{mM})$ & $\mathrm{Fe}(\mathrm{II})$ oxalate 7.5 & $\mathrm{Fe}(\mathrm{II})$ oxalate 17.0 \\
\hline 10 & 3.0 & 6 & 8.0 & 8.2 \\
30 & 3.0 & 6 & 70.3 & 81.6 \\
50 & 3.0 & 6 & 80.5 & 87.5 \\
70 & 3.0 & 6 & 84.7 & 90.6 \\
30 & 2.0 & 6 & 61.6 & 71.8 \\
30 & 3.5 & 6 & 39.8 & 44.3 \\
30 & 3.0 & 3 & 67.3 & 75.4 \\
30 & 3.0 & 12 & 64.6 & 78.1 \\
30 & 3.0 & 24 & 66.2 & 74.6 \\
\hline
\end{tabular}
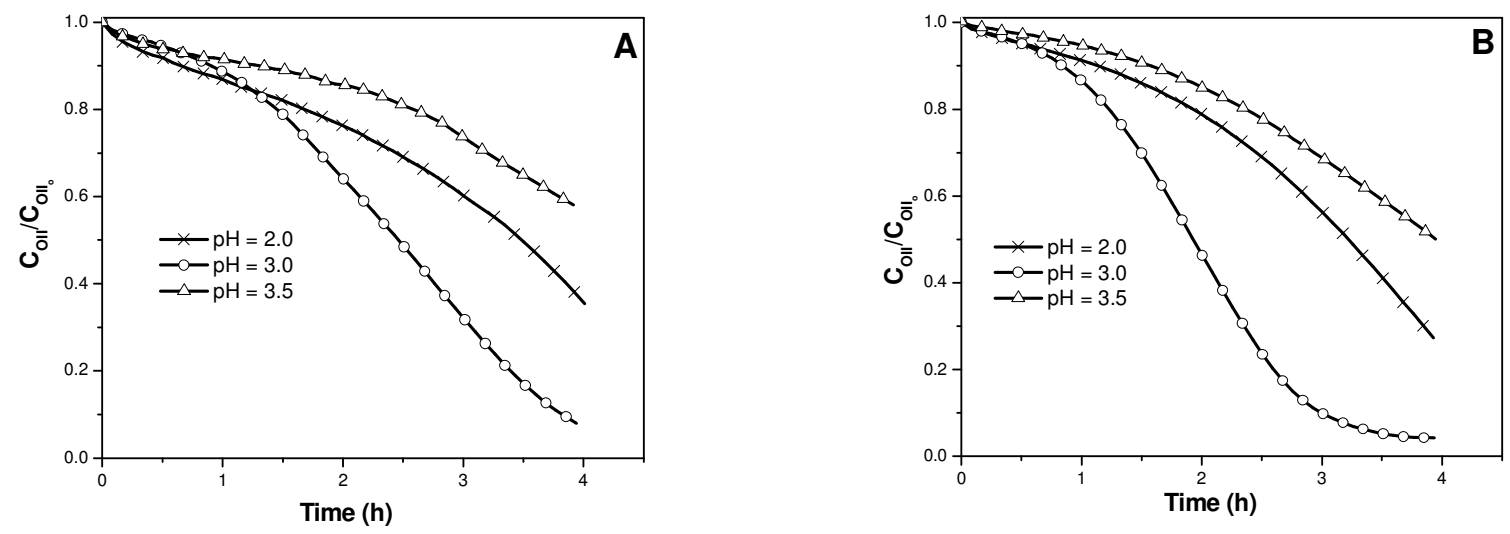

Figure 3. $\mathrm{pH}$ effect on the degradation of OII solution using different catalysts:

(A) Fe(II) oxalate 7.5 wt. $\%$ and (B) $\mathrm{Fe}(\mathrm{II})$ oxalate $17 \mathrm{wt} . \%\left(\mathrm{C}_{\mathrm{H} 2 \mathrm{O} 2}=6 \mathrm{mM}, \mathrm{T}=30^{\circ} \mathrm{C}\right)$.

Figure 4 shows the effect of the reaction $\mathrm{pH}$ on the iron leaching. It is clear that iron lost is more significant at $\mathrm{pH}$ 2.0 , especially for the $7.5 \mathrm{wt}$ \% catalyst. Therefore, for long-term stability it would be preferable to work at higher $\mathrm{pH}$ values. Feng et al. (2006) also found that iron leaching was much more significant at $\mathrm{pH}$ around 2 . The $\mathrm{Fe}$ leaching at this low initial solution $\mathrm{pH}$ can be attributed to the dissolution of iron oxide at very acidic conditions.

At $\mathrm{pH} 2.0$ the amount of iron leached into solution is much higher for the $7.5 \mathrm{wt} \%$ catalyst than for the $17.0 \mathrm{wt} . \%$ one (Fig. 4A vs. 4B), even though the catalytic performance is not better (Fig. 3A vs. 3B), thus supporting the importance of the heterogeneous catalytic process. On the other hand, it is noteworthy that in the $\mathrm{pH}$ range studied (2.0-3.5), the sample with more iron (17.0 wt.\%) shows similar or even lower percentages of iron lost, and thus can be in practice used for more operation cycles.

\section{$\mathrm{H}_{2} \mathrm{O}_{2}$ Concentration effect}

The initial hydrogen peroxide concentration was varied between 3 and $24 \mathrm{mM}$, using the same catalysts as in previous sections. The obtained results (Fig. 5) show, for both samples, a similar behavior in terms of dye degradation for the intermediate $\mathrm{H}_{2} \mathrm{O}_{2}$ concentrations $(6$ and $12 \mathrm{mM})$, whereas the reaction goes by more slowly when the concentration is smaller $(3 \mathrm{mM})$ or higher $(24 \mathrm{mM})$. The increase of the oxidant concentration from 3 to $12 \mathrm{mM}$ leads to an increase in the reaction rate, as expected, because more radicals will be formed. Nevertheless, for a very high hydrogen peroxide concentration $(24 \mathrm{mM})$ the performance decreases. The existence of an optimum hydrogen peroxide concentration is typical and well-known in Fenton's oxidation. This optimum value was previously found by us to be $10 \mathrm{mM}$ for OII degradation in homogenous Fenton reaction, using catalytic iron sulphate (Ramirez, et al., 2005). At higher $\mathrm{H}_{2} \mathrm{O}_{2}$ concentrations the scavenging of $\mathrm{HO}^{\circ}$ radicals will occur, which can be expressed by the following reaction: 


$$
\mathrm{H}_{2} \mathrm{O}_{2}+\mathrm{HO}^{\bullet} \rightarrow \mathrm{H}_{2} \mathrm{O}+\mathrm{HO}_{2}{ }^{\bullet}
$$
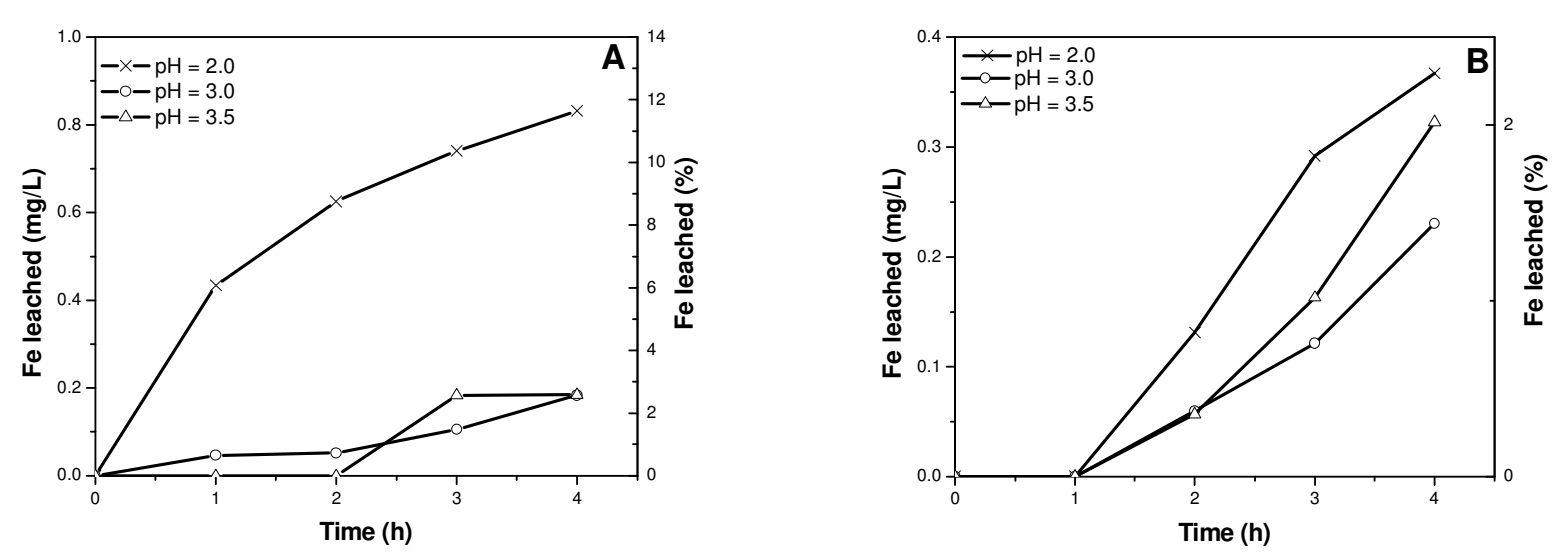

Figure 4. Iron leaching for experiments at different $\mathrm{pH}$ values and using different catalysts:

(A) $\mathrm{Fe}(\mathrm{II})$ oxalate 7.5 wt. $\%$ and (B) $\mathrm{Fe}(\mathrm{II})$ oxalate 17 wt. $\%\left(\mathrm{C}_{\mathrm{H} 2 \mathrm{O} 2}=6 \mathrm{mM}, \mathrm{T}=30^{\circ} \mathrm{C}\right)$.

The influence of the $\mathrm{H}_{2} \mathrm{O}_{2}$ concentration on the mineralization (Table 1) is similar as for decolourisation, with an optimum oxidant concentration of $6 \mathrm{mM}$ for both catalysts. In spite of the final performances attained seem to be only slightly affected by the peroxide dose, it is clear that for $\mathrm{H}_{2} \mathrm{O}_{2}$ concentrations above that value the final TOC removal decreases a little bit, this effect being similar to those reported by other researchers (Dutta, et al., 2001; Guedes, et al., 2003). Regarding iron leaching, it is noteworthy that, once again, the concentrations reached are always small (below $0.4 \mathrm{mg} / \mathrm{L}$ for both samples).
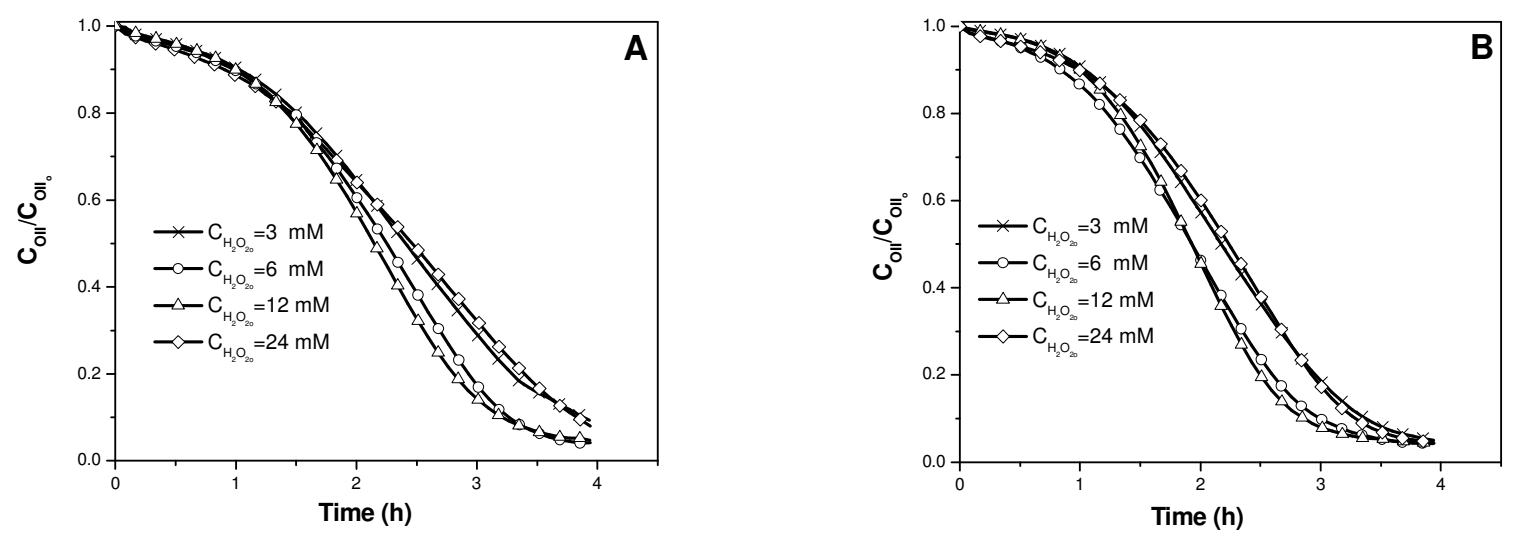

Figure 5. Effect of the hydrogen peroxide concentration on the degradation of OII solution using different catalysts: (A) $\mathrm{Fe}(\mathrm{II})$ oxalate 7.5 wt. $\%$ and (B) $\mathrm{Fe}(\mathrm{II})$ oxalate $17 \mathrm{wt} \%\left(\mathrm{pH}=3.0, \mathrm{~T}=30^{\circ} \mathrm{C}\right)$.

Finally, it is important to remark that we have performed some tests to evaluate the stability of the most promising catalyst (i.e., with low iron leaching and good catalytic performance): the Fe (II) oxalate 17.0 sample. OII degradation and TOC reduction were evaluated in 4 consecutive runs, being the catalyst recovered by filtration of the final effluent. Even though a slight activity decay was observed, which might be due to the iron loss (ca. $1.5 \%$ per cycle that represents a final concentration smaller than $0.3 \mathrm{mg} / \mathrm{L}$, data not shown), OII conversion decreases only from 95.8 to $90.3 \%$ in 4 cycles, i.e., 16 h of operation. Regarding TOC reduction, in the 4 cycles final values were: 81.6, 81.4, 78.5 and $77.1 \%$. In practice, this small deactivation could be compensated, if required, by adapting the reaction conditions (for instance slightly increasing the temperature along time).

\section{Conclusions}

- Twelve supported Fe-saponite catalysts have been prepared, by means of the incipient wet impregnation method, using a pillared clay support and four salts of Fe precursors at different Fe loads. The characterization of the 
catalysts shows that the decomposition of the precursors gives rise to solids that present laminar structure, with active phases of Fe highly dispersed on the support, and high specific surfaces (in most of the cases with values comprised between 130 and $170 \mathrm{~m}^{2} / \mathrm{g}$ ), characteristics that make them potentially good catalysts for oxidation in the Fenton-like process.

- All the catalysts revealed to be quite active in the Fenton-like oxidation of Orange II, once clay concentrations used are much below than those usually found in the literature (typically around $1 \mathrm{~g} / \mathrm{L}$ ).

- The effects of hydrogen peroxide concentration, temperature and $\mathrm{pH}$ of the reaction medium were analysed in the present work. The obtained results show a high degradation of OII and of the intermediary oxidised compounds. At optimal conditions, $99 \%$ discoloration and $91 \%$ of mineralization were reached (after $4 \mathrm{~h}$ of reaction), using the catalyst prepared from $\mathrm{Fe}(\mathrm{II})$ oxalate with $17.0 \mathrm{wt} \%$ of $\mathrm{Fe}$ and in the following reaction conditions: $\mathrm{T}=70^{\circ} \mathrm{C}, \mathrm{pH}=$ 3.0 and $\mathrm{C}_{\mathrm{H} 202}=6 \mathrm{mM}$. However, good performances with high selectivities to $\mathrm{CO}_{2}$ and $\mathrm{H}_{2} \mathrm{O}$ were also reached at significantly lower temperatures $\left(30^{\circ} \mathrm{C}\right)$.

- All the catalysts exhibit not only good catalytic activity but also a reasonable small iron leaching (below the EU directives values), indicating that the active phases are strongly fixed to the support (possibly iron strongly bonded to the aluminium pillars or engaged in small oxide clusters dispersed in the solid, inside or outside the porosity). This characteristic makes possible the Fe-saponite catalysts to have long-term stability, without generating iron hydroxide sludges.

\section{Acknowledgements}

J.H. Ramirez wishes to express his gratitude to FCT for the PhD grant (ref.: SFRH/BD/24435/2005). The authors also acknowledge the financial support from CRUP, Portugal and the Spanish Ministerio de Educación y Ciencia.

\section{References}

Barrault, J., Tatibouët, J. M., and Papayannakos, N. (2000). Catalytic wet peroxide oxidation of phenol over pillared clays containing iron or copper species. C. R. Acad. Sci. Paris, Serie IIc, Chimie : Chemistry, 3, 777-783.

Belver, C., Banares-Munoz, M. A., and Vicente, M. A. (2004). Fe-saponite pillared and impregnated catalysts: I. Preparation and characterisation. Appl. Catal. B: Environ, 50, 101-112.

Bottero, J. Y., Cases, J. M., Flessinger, F., and Porlrier, J. E. (1980). Studies of hydrolized aluminium chloride solutions. 1. Nature of aluminium species and composition of aqueous solutions. J. Phys. Chem, 84, 2933-2939.

Catrinescu, C., Teodosiu, C., Macoveanu, M., Miehe-Brendle, J., and Dred, R. L. (2003). Catalytic wet peroxide oxidation of phenol over Fe-exchanged pillared beidellite. Water Res, 37, 1154-1160.

Dutta, K., Mukhopadhyay, S., Bhattacharjee, S., and Chaudhuri, B. (2001). Chemical oxidation of methylene blue using a Fenton-like reaction. J. Hazard. Mater, B84, 57-71.

Feng, J., Hu, X., and Yue, P. L. (2006). Effect of initial solution pH on the degradation of Orange II using clay-based Fe nanocomposites as heterogeneous photo-Fenton catalyst. Water Res, 40, 641-646.

Gallard, H. and De Laat, J. (2001). Kinetics of oxidation of chlorobenzenes and phenyl-ureas by $\mathrm{Fe}(\mathrm{II}) / \mathrm{H}_{2} \mathrm{O}_{2}$ and $\mathrm{Fe}(\mathrm{III}) / \mathrm{H}_{2} \mathrm{O} 2$. Evidence of reduction and oxidation reactions of intermediates by $\mathrm{Fe}(\mathrm{II})$ or $\mathrm{Fe}(\mathrm{III})$. Chemosphere, 42, 405-413.

Gemeay, A. H., Mansour, I. A., El-Sharkawy, R. G., and Zaki, A. B. (2003). Kinetics and mechanism of the heterogeneous catalyzed oxidative degradation of indigo carmine. J. Mol. Catal. A: Chem, 193, 109-120.

Guedes, A. M. F. M., Madeira, L. M. P., Boaventura, R. A. R., and Costa, C. A. V. (2003). Fenton oxidation of cork cooking wastewater--overall kinetic analysis. Water Res, 37, 3061-3069.

Guo, J. and Al-Dahhan, M. (2003). Catalytic wet oxidation of phenol by hydrogen peroxide over pillared clay catalyst. Ind. Eng. Chem. Res, 42, 2450-2460.

Lahav, N., Shani, V., and Shabtai, J. (1978). Cross-linked smectites. I. Synthesis and properties of hydroxy-aluminummontmorillonite. Clays Clay Miner, 26, 107-115.

Letaief, S., Casal, B., Aranda, P., Martín-Luengo, M. A., and Ruiz-Hitzky, E. (2003). Fe-containing pillared clays as catalysts for phenol hydroxylation. Appl. Clay Sci, 22, 263-277.

Ramirez, J. H., Costa, C. A., and Madeira, L. M. (2005). Experimental design to optimize the degradation of the synthetic dye Orange II using Fenton's reagent. Catal. Today, 107-108, 68-76.

Ramirez, J.H., Costa, C.A, Madeira, L.M., Mata, G. and Vicente, M.A (2006). Preparación, caracterización y comportamiento catalítico de catalizadores basados en saponita para la oxidación de Orange II en disolución acuosa. In: Materiales arcillosos: de la geología a las nuevas aplicaciones. Suárez, M et al. (Eds.), Sociedad Española de Arcillas, Salamanca, Spain, 123-137.

Swaminathan, K., Sandhya, S., Sophia, A. C., Pachhade, K., and Subrahmanyam, Y. V. (2003). Decolourization and degradation of $\mathrm{H}$-acid and others dyes using ferrous-hydrogen peroxide system. Chemosphere, 50, 619-625.

Vicente, M. A., Gil, A., and Gandia, L. M. (2000). Recent advances in the synthesis and catalytic applications of pillared clays. Cat. Rev. Sci. Eng, 42, 145-212. 